This item was submitted to Loughborough's Research Repository by the author.

Items in Figshare are protected by copyright, with all rights reserved, unless otherwise indicated.

\title{
Parental stressors in professional youth football academies: a qualitative investigation of specialising stage parents
}

\section{PLEASE CITE THE PUBLISHED VERSION}

http://dx.doi.org/10.1080/19398440903510152

\section{PUBLISHER}

Routledge (@ Taylor \& Francis)

VERSION

AM (Accepted Manuscript)

\section{LICENCE}

CC BY-NC-ND 4.0

\section{REPOSITORY RECORD}

Harwood, Chris G., Ashleigh Drew, and Camilla J. Knight. 2019. "Parental Stressors in Professional Youth Football Academies: A Qualitative Investigation of Specialising Stage Parents". figshare.

https://hdl.handle.net/2134/15211. 
This item was submitted to Loughborough's Institutional Repository (https://dspace.lboro.ac.uk/) by the author and is made available under the following Creative Commons Licence conditions.

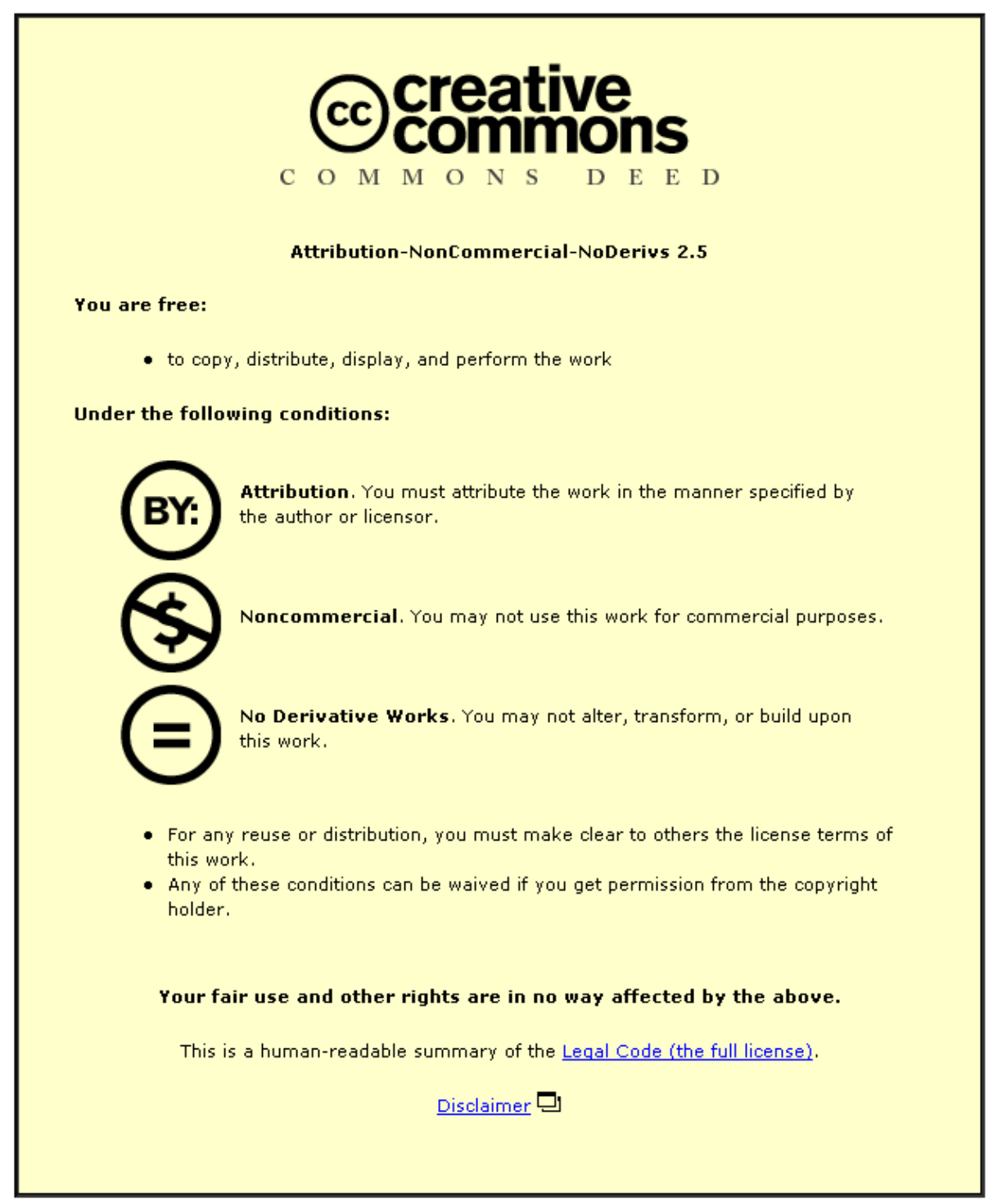

For the full text of this licence, please go to: http://creativecommons.org/licenses/by-nc-nd/2.5/ 
Parental stressors in professional youth football academies: A qualitative investigation of specializing stage parents

C.G.Harwood, A. Drew \& C.J. Knight (in press)

Qualitative Research in Sport and Exercise

Personal Use only 


\section{Abstract}

In order to improve our understanding of parental experiences in elite youth sport, the present study investigated parental stressors within the context of professional football (i.e., soccer) academies in Great Britain. Focusing upon the specializing stage of athlete development (Côtè \& Hay, 2002), a total of 41 parents attended six focus groups exploring their experiences of stressors during the early and later phases of the specializing stage. A hierarchical thematic content analysis led to four dimensions of parental stressor: academy processes and quality of communication; match-related factors; sport-family role conflict; and school support and education issues. Parents across the entire specializing phase identified uncertainty of their son's retention in the academy and quality of communication with staff as significant ongoing stressors. Unfamiliar coaching and match practices emerged as stressors for early stage parents, whereas the management of school and academy demands were most prominent for later stage parents. Their experiences suggested that management of a parent's expectations for their child in an academy, and the ability for a professional club to communicate its 'developmental' and 'non-developmental' practices might be central to parental support and well-being. Strategic implications for practitioners, coaches and organisations are presented with these findings in mind.

Key words: parent, stress, football, development, youth sport 
Parental stressors in professional youth football academies:

A qualitative investigation of specializing stage parents

It is perhaps a sad indictment of today's youth sport culture when we read reports of parental abuse towards young athletes (DeFrancesco \& Johnson, 1997; Shields, Bredemeier, LaVoi, \& Power, 2005), tragic fights between parents, young athletes and referees (CBS, 2006; Wong, 2001), and one tennis father's recent conviction for manslaughter after he drugged his teenage son's opponents causing one of them to be fatally injured (Lichfield, 2006). Programs in youth football (i.e., soccer) within the United States have inaugurated fan behavior induction seminars for parents and 'Silent Saturdays or Sundays' as a behavioral deterrent against excessive verbal abuse, inappropriate coaching from the sidelines and sideline rage (see Wong, 2001).

Yet whilst there is an extensive body of popular literature and research on the roles and behaviors of parents from both negative and positive perspectives (Baxter-Jones \& Maffuli, 2003; Fish \& Magee, 2001; Gould, Lauer, Rolo, Jannes \& Pennisi, 2006, 2008; Hellstedt, 1990; Holt, Tamminen, Black, Zehn \& Wall, 2008; Hoyle \& Leff, 1997; Leff \& Hoyle, 1995), there is a limited academic understanding of the stressors and issues experienced by parents as they support their child through the stages of sport development (Côtè, 1999). If youth sport programs and organizations seek to optimize the role of sport parents, then it is important to appreciate parental constructions of stress and explore the inherent stressors that may impact on the quality of their 'performance' and role with the child-athlete (see Gould et al., 2006, 2008; Holt et al., 2008).

The roles of parent and child in the youth sport environment are clearly very different. Parents serve as provider, interpreter and role model for the young athlete who is effectively a user or consumer of the sport experience (see Green \& Chalip, 1997; Fredricks \& Eccles 2004; Wuerth, Lee \& Alfermann, 2004). The provision of logistical opportunities, finance, and transport as organizational demands, are equally matched by the emotional demands of 
1 competition and the importance of reacting to all competitive events in adaptive and

2 supportive manners. According to Fredricks and Eccles (2004) the degree to which these

3 roles are fulfilled by parents serves to influence a child's beliefs and values and in turn, their

4 motivated behaviors and performance.

Research has illustrated how the time commitment required from parents can impede their occupational, social, and family life (Kirk et al., 1997b), causing particular strain if their time and attention becomes centered upon one child-athlete at the expense of non-sport siblings. Further, from a financial perspective, Kirk and colleagues (1997a) concluded that the economic costs of junior sport can negatively affect both a child’s sport participation and impact more widely throughout family life. Baxter-Jones and Maffuli (2003) corroborated these findings within a tennis-specific sample identifying that approximately $12 \%$ of the family budget was spent on tennis, with $16 \%$ of parents reporting severe financial hardship as a consequence.

From a conceptual perspective, researchers have recently made the distinction between those stressors linked specifically to competition and competitive performance (i.e., competitive stress) with the stressors associated primarily with the organization within which the individual is operating (i.e., organizational stress; Fletcher, Hanton, \& Mellalieu, 2006; Hanton \& Fletcher, 2005; Woodman \& Hardy, 2001). In conducting this research, these investigators have essentially viewed stressors as a 'sensitizing’ concept (Blumer, 1954, 1969; Patton, 2002) with their intention focused on refining our understanding of the multiple ways in which overall (elite) sport participation can be psychologically demanding from the perspective of the protagonist. As Charmaz (2003) notes, "sensitizing concepts offer ways of seeing, organising and understanding experience; they are embedded in our disciplinary emphases and perspectival proclivities” (p. 259). For sport psychologists, this research has reinforced the importance of understanding stress as a social construct that resides within athletes. However, it is clear that many of these stressors may be shared by parents. Indeed, 
1 within youth sport, organizational stressors such as finance, travel, sport policies and

2 interpersonal conflict are more likely to frame the parent's experience as opposed to the child3 athlete's.

4

In establishing a line of research that specifically targeted parental perspectives, Harwood and Knight (2009a) investigated the stressors articulated by 123 British tennis parents. The wide range of stressors emerging from their open-ended survey coalesced into seven core themes of parental stress. These included stressors associated with attendance at competitive matches and tournaments; coaches' behaviors and responsibilities; financial and time demands placed upon the family; sibling resentment and inequality of attention; inefficiencies and inequalities attributed to tennis organizations; and developmental concerns related to educational and future tennis transitions.

A limitation of this research was the inability to focus on parental stressors associated with a specific stage of their child’s sport development. Côtè (1999) identified four stages of participation: sampling, specializing, investment, and recreation. His model traces the intensity of sport participation from early childhood to late adolescence and identifies differences in the experiences and requirements of athletes during each stage. The role and requirements of parents have also been noted to progressively change through the sampling, specializing and investment stages (see Côtè, 1999; Côtè \& Hay, 2002).

Harwood and Knight’s (2009a) study was subsequently extended by conducting qualitative interviews with eighteen tennis parents whose children were currently at one of these three stages of participation (Harwood \& Knight, 2009b). Their results reinforced the prominence of competitive, organizational and developmental stressors identified through the survey. However, stage-specific analyses suggested that the specializing stage parents experienced and shared the greatest range of stressors compared to the other two phases. Whilst these prior studies serve to assist coaches and relevant tennis organizations in empathizing with parental demands and educational needs, the experience of parents in an 
1 organized team sport context is lacking. Consequently, in progressing this area, the present

2 study investigates parental stressors within a team sport, focusing specifically on the

3 specializing stage of athlete development.

British football parents whose children had signed for a professional football club academy were purposely selected for the project as they represent a rather unique group of individuals. Within British football, unlike all other team sports in the UK, talented players are scouted and inaugurated into a 'professional club’ academy system at as young as eight years of age with financed coaching offered for up to seven more years. Whilst de-selection (i.e., release) is a yearly process, young players may retain their place as an 'academy schoolboy' up to 16 years of age. At this point, players may enter the professional (i.e., investment stage) domain as an 'academy scholar' if they are one of the few selected for this next stage. With considerable weekly time commitments, the specializing stage of development is a lengthy process (i.e., seven years), with parents potentially experiencing a variety of different stressors as their child progresses through this stage. Supported by the Football Association of England (the FA), the present study therefore focuses on the experiences of academy football parents across the specializing stage, with delineated attention to the differing stressors associated with younger and older players within this phase of development.

Method

\section{Philosophical orientation and methods}

This study was essentially grounded in a postpositivist paradigm (Campbell, 1999), and supported a critical realist philosophy (Bhaskar, 1975; Miles \& Huberman, 1994; Sayer, 2000). In this respect, we do not believe in one unitary truth about stress, but we do believe that stressors exist in the real world of youth football; that they are complex, subjective and that they affect lives. We believe that a more accurate and valid truth about stressors in academy football parents is possible and that this might be constructed through dialogue with 
1 members of that community in activating the respondents 'stock of knowledge' (Ritchie \&

2 Rigano, 2001). Therefore, as opposed to simply testing whether soccer is stressful for parents

3 and establishing specific mechanisms of influence, our focus was firmly upon learning,

4 discovery and then interpretation of the reality of being a 'football parent' vis a vis the

5 sensitizing concept of stressors that were meaningful to them.

To most appropriately investigate this question, we targeted the community of football parents and pursued a focus-group methodology with parents from three different professional youth academies. Though under-utilized in social-psychological research, focus group interviews are well suited to gaining in-depth responses and facilitating a large amount of group interaction on a specified topic over a small period of time (Morgan, 1997). In this specific study, focus group interviews were particularly useful and advantageous in gathering richer data than might have been expected through individual interviews. Specifically, they offered the possibility of collaborative sharing amongst participants and the stimulation of new perspectives and spontaneous insights that would have been less likely in one-to-one settings. These possibilities were optimised in this study because all of the parents were part of the football academy community and the opportunity for enhanced interaction and richer discussion around parent-role stressors was perceived to be greater given their common experience of the same club. In addition, it was considered important to listen to the stories and interactions of parents who were all in the early specializing stage compared with those parents who shared their experiences of supporting later specializing players.

\section{Participants}

Participants were drawn from three professional football club academies within the north, midlands, and south of England. In total, 41 participants, 25 fathers and 16 mothers, participated in one of six focus groups. In order to investigate whether specific stressors develop or change across the specializing stage, three focus group interviews were conducted with parents from two academy age ranges: The U9's to U12's (early specializing) and the 
1 U13's to U15's (later specializing). The twenty two parents in the U9-U12 groups considered

2 themselves to have been in the role of 'football parent' for an average of 5.25 years (SD:1.76),

3 whereas the nineteen U13-U15 parents reported an average of 7.26 years (SD:2.38)

4 experience.

$5 \quad$ Procedure

Following completion of all ethical clearance procedures, Academy Managers from three football academies were approached via logistical assistance from the FA to assist in parental recruitment. Participants were sent a letter prior to the focus group interview, explaining the purpose of the study, as well assuring the confidentiality of their responses. Demographic information was collected along with participants' informed consent. proposed by Krueger and Casey (2000). All participants received a standardized introduction, explaining the aim and format of the focus group and the role of the moderator. More important to the integrity and value of the focus group approach, however, was the careful distribution of only two or three parents from the relevant age groups (i.e., U9 to U12; U13 to U15) into each stage-related focus group. This ensured that no single age group or clique of parents dominated a particular focus group discussion. Parents shared their experiences openly and collaborated with parents of children who were in slightly younger or older age groups within that specific stage at the same club. (2009a,b) with sensitivity to covering a broad range of contexts relevant to competition, organizational, and developmental aspects.. An introductory question allowed parents to get to know each other before focusing the interaction on their general experiences of stressors within the youth academy. Subsequent questions and probes served to stimulate discussion around contexts such as matches and training, coaches and academy systems, finance and 
1 time, personal and social aspects, and education and development. Most critically, closing

2 questions allowed the moderator to check parents' had shared all experiences that they felt

3 were important to them. Each of the focus groups were videoed and recorded, ranging from

453 to 65 minutes length (M: 57.5 minutes; $S D: 4.65)$.

5 Data analysis

Data from the focus groups were transcribed verbatim and a hierarchical thematic content analysis was conducted that incorporated both inductive and deductive elements

8 (Côtè, Salmela, Baria \& Russell, 1993; Krueger \& Casey, 2000; Miles \& Huberman, 1994).

9 As noted earlier, a stressor was used as a sensitizing concept (Blumer, 1954) about which prior studies (e.g., Harwood \& Knight, 2009a,b) had gained initial insights within an 'individual sport' setting . Therefore, prior knowledge around stressors in parents did exist and it should be acknowledged that the contexts in which stressors were reported served, albeit informally, as useful reference points for the initial stages of analysis. However, the authors were careful to ensure that the deductive element of this process ended there, and that progressively inductive data interpretation guided the research team towards nonpredetermined themes of stressor. Such induction was facilitated given that no research to date had interviewed youth soccer parents about any aspect of their experience of being a parent in a professional academy.

Following data collection, meaningful comments and quotes from the raw data that were interpreted as a stressor were coded as a meaning unit or essence phrase (Maykut \& Morehouse, 1994). These essence phrases enabled the development of raw data themes that essentially represented a list of similar quotes emerging from the parents. This analytical process then progressed inductively to a higher thematic level whereby raw data themes were clustered around a common, underlying higher order category. Field notes and video footage were checked in-between groups in order to ensure the moderators’ ongoing insight and familiarity with the emerging data. Further hierarchical categorizations that represented these 
1 higher order categories and their raw data themes emerged in the form of general dimensions.

2 Careful data management within and between the different focus groups ensured the

3 identification of reported stressors that were shared by both early and later specializing stage

4 parents, as well as themes specific to each phase alone (see Results section).

5 Methodological rigor

Although the processes of reliability and validity in qualitative research remain contentious areas of debate (Patton, 2002; Sparkes \& Smith, 2009), we supported the importance of optimising these elements of our data analysis, particularly given our research

9 goal of developing a credible and collaborative understanding of the stressors faced by football parents in the specializing stage. Trustworthiness in this case was facilitated by two main methods focused on enhancing this level of credibility and minimizing researcher bias related to the interpretive analysis of the second author (Johnson, 1997; Lincoln \& Guba, 1985). Firstly, investigator triangulation processes involved the first and third authors independently coding one separate transcript from each focus group classification (i.e., early and later specializing) as part of an inter-coder consistency check on the initial interpretations of the second author (Lincoln \& Guba, 1985). A 79\% level of intercoder reliability emerged which led to discussion, agreement and minor coding revisions. Following this process, the first author reviewed the interpretive allocation and labelling of the raw data themes into their higher order theme. He repeated this verification process for the allocation of higher order themes into subsequent general dimensions. Interpretations were openly discussed and challenged appropriately at each stage with a final consensus achieved. At this end point, the third author then served in the capacity of a peer-debriefer or 'critical friend' (Cresswell, 1998) by reviewing the emergent framework as a whole and critically probing for explanations of certain decisions made by the two other research colleagues. 
1 framework. Documents were sent out to a randomly selected review panel of participants in each focus group. Beyond being asked to verify their verbal contributions to the focus group, they also received an illustration of the emergent themes and finalized hierarchy from the study, alongside an explanatory summary. The entire review panel validated the information and interpretations related to their group, and agreed that the final thematic hierarchy was an accurate, plausible and authentic representation of parental stressors across the specializing stage.

\section{Results}

Over the six focus groups, 77 raw data themes emerged from the analysis. These themes coalesced into 23 higher order sub-themes which were subsequently categorized into four general dimensions of parental stressor. These were: academy processes and quality of communication; match-related stressors; sport-family role conflict; and school support and education issues. Figure 1 illustrates the content of these four dimensions, their corresponding themes, and differentiates between those themes that were specific to either specializing phase, or common to both phases. Each general dimension will be elaborated upon using specific quotes from parents. Each quote is identified by a parent ID number. (e.g., P3), the number of the focus group (e.g., F2) and whether it was a later or early specializing stage group (e.g., P3;F2;Later).

\section{Academy processes and quality of communication}

All focus groups raised issues that were inherent to the processes and systems of the academy, particularly with respect to the flow of communication and information to parents related to the security of their child's place. Firstly, a sense of fear and uncertainty about signing their child with the academy emerged for a number of parents. One parent stated: A parent's natural instinct is to protect their child and make sure they feel confident in themselves. Therefore, anything that may open them up to failure or lowering their self- 
esteem. you worry about; you want them to have the opportunity, but you want to protect them (P1, F3, Early).

Fear of signing was inextricably related to the fear of failure and prospect of release from the academy. Parents expressed that their sons' potential reactions to release and the possibility of any long-term effects due to release were particularly stressful. The following extract from focus group 3 (later specializing) captures the essence of the theme here:

P1: There were some lads who'd all been together since they were 8 (years old) and quite a few of them went (i.e.,were released). I was stood out there having my cup of tea and players were coming out [of the meeting] like this (wiping tears) and having to walk in there [the dressing room] to the rest of the lads.

P5: You feel like they’ve had a big failure and I wonder what knock on effect it'll have in later life.

P2: One of my son's friends was at XX academy from 8 to 16, when he got released he was on valium and all and in a right mess.

P6: You know the longer they are in, the harder the fall cos they are in it longer and longer. And as they get older there are so many things going on in their lives which you're worried about... and you really want to prepare them for something that's going to be as devastating as this to these guys. By the time they've been doing it for this long they really really do want to do it, they're so keen, and its huge blow. P2 (whose son was in that specific team): My son said to me, 'Dad, if I get released I don't want to go through there [i.e., the door back to the dressing room]'. He didn't want all the people coming to him saying ‘sorry’. He wanted to go out of that door [he points to the fire escape]. So if he'd got released we'd have gone out of that door, and we'd have gone home.

Parents understood that difficult decisions about player retention had to be made by coaching staff, yet this did not counteract the feelings of uncertainty concerning decisions about 
1 their own child and the lack of preparation or forewarning that was perceived. Additionally,

2 parents in later stage focus groups referred to how releases are handled by the academy citing

3 examples of insensitive comments and processes where players are released prior to training

4 sessions. Many were concerned about the lack of empathy or due consideration for the future

5 welfare of their child and the time devoted to the academy. One parent stated: My son was at XX Academy for three months and his coach comes up to us and says 'I'm really pleased with this squad and I've got no reason at all to change this for a year' and I said to my son ' well you're fine then'. The following week it was 'you, you, you, you and you are finished'. That was a week after they were told they were gonna be there for a year! (P1, F3, Later)

Early specializing parents in all focus groups referred to difficulties they encountered through the limited information they received from their academy before and on signing their child, and a lack of education about expectations and procedures ("It's the unknown when you join a club like this and the lack of information”(P3, F2, Early). This was also closely aligned to perceptions of poor feedback that proved frustrating for parents when their son was on trial for the academy: "It was stressful for me not knowing whether he was in or not. I mean it had been that long....three months and no information. As a parent you get stressed and you're thinking 'is it worth it?' ” (P3, F1, Early).

Many parents noted the inadequate communication after their son joined the academy. A consistent theme from each of the six focus groups was the poor quality and regularity of feedback that parents received about their son’s progress. A sense of frustration was evident not only in terms of frequency of feedback, but also the validity and inconsistency of the feedback One parent challenged feedback quality, targeting the superficiality of their academy's simple grading system:

We had a report after every game but he wasn’t taking him to one side and saying how to sort a problem out. You can get given a D because you aren’t doing it correctly, and 
the next week he is given a B and he hadn’t changed anything! And he’s not actually told him how to change it either. (P5, F2, Later)

Finally, parents cited the inconsistent behavior of coaches and how they sometimes failed to support and appreciate the logistical and personal demands of their family role. One father recalled:

We couldn’t make a particular Sunday game and I'd seen the coach the week before and he'd said 'don't worry, no problem'. Then the Wednesday game comes along, which is quite important, and he says ‘sorry you can’t go [i.e., my son can’t play] because you never turned up! [on Sunday]. They don't see the other side of it when you're at home trying to console your upset child saying ‘don’t worry about it!' (P3, F2, Early)

Perceptions of limited empathy and understanding when faced with difficult family choices or circumstances was exemplified by three further parents. One stated: “You know I’m dashing to drop one lad off at XX Academy boys training and then shoot off over here with another lad. It's a given really isn't it in this sort of environment, they expect that at 7 o'clock the fairies will drop them off” (P2, F2, Later). The second parent recounted:

It was my son's best friends birthday party and he wanted to go so I rang the coach early that week to let them know that he couldn't play. The next time we went to the academy the look we got from the coach....it made you feel 'ahhh, may be we shouldn't have said or done that' but at the time we felt it was the right thing to do because our son was only 8 years old. (P4, F3, Early)

While the third parent recalled:

My son broke his arm in pre-season training this year and I was really upset that we didn't get a phone call from the club. It affected my boy as well because he couldn't understand why the coach or whoever didn't ring to see how he was doing. He’s been missing for seven weeks and I think they've got to understand the stress the boys are under. (P3, F2, Early) 


\section{Match-related stressors}

All focus group parents shared a number of experiences associated with their son's participation in competitive matches, although their child's performance [and resultant anxieties around mistakes] emerged as a theme in only one late specializing focus group: Watching him play - that is stress. I mean it's the most stressful time for me. I mean when they played XX team that was awful - I wanted him to come off in case he made a mistake. He's a defender as well and with the youth team coach coming to watch, I thought if he touches the ball and makes a mistake, then that's it! (P3, F3, Later)

Another parent, in the same group, followed up by disclosing how she only watches the game if the other goalkeeper [i.e., not her own son] is playing:

It's just a nightmare, I can’t even watch.....I'm more relaxed watching the other goal keeper because it’s not my son in goal. But when he’s actually in goal I'm just scared. I mean I don’t know why I put myself through it, I should just sit in the car, I don’t know why I bother I really don't. (P5,F3,Later)

Later specializing parents also discussed their experiences around their sons' reactions to losing matches and the negative anticipation of what the after-match mood was going to be like which they felt they had to deal with.

A further cluster of match-based issues revolved around coaching and coaches’ decision-making regarding players and tactics in matches. Some early stage parents struggled to resist interfering in matches by coaching or instructing their son from the sidelines, whilst most focus groups raised the issue of coaches rotating players and making incomprehensible substitutions: “As long as I live I will never ever work out coach decisions, when they take people off when they put people on and I'm not alone. We sit there going 'why've they done that?'” (P6, F3, Later). Some early stage parents also spoke negatively [and passionately] about the coach's practice of moving their son into different playing positions, and in some cases, with insufficient feedback and explanation to the 
1 player and parent as to why. Most interestingly, this issue was closely allied with the

2 problems some parents cited with respect to match-winning situations being sacrificed in

3 favour of achieving developmental goals. A number of parents referred to the emotions

4 they experienced when watching matches where the team were winning, only for the coach

5 to change the team or tactics [for developmental reasons]:

I find it straining that they'll put the best team on with the lads playing their positions and then when they are 2 or 3 [goals] up in the last 20 minutes they'll say 'right' and put different lads on......and then we end up losing the game (P5, F1, Early)

A further group of early specializing parents also reacted negatively to the introduction of small sided (5-a-side) mix-in games that had been organized in favour of full competitive fixtures. They viewed these developmental games as just another training session that they felt did not test players competitively and many cited that they would not watch these types of games if they knew in advance that this was the format.

Negative encounters with other football parents were reported as

infrequent, however, a number of parents disclosed unpleasant touchline comments directed at their son which they found personally difficult to cope with: "I find it hard to deal sometimes with parent's comments that you can hear if they stand there; it's really hard and I stand there and I'm quite shy so I don’t react - so it’s really hard.”(P5, F3, Later).

Finally, stories about injury emerged in both early and late specializing groups as parents shared their experience of physical worries for their son. Fear of injury appeared to increase in conjunction with the increased physicality of the game and physical development of players. However, due to the pressured competition environment characteristic of later specializing players vying for contracts, the negative compensatory 
1 behaviors of overtraining, and masking injuries were particularly worrying for parents of

2 older players. This is illustrated in the quote below:

"See that's a stress as well for me - rushing them back from injury; they rush themselves back. This player goes out and plays with an injury he’s trying to mask it but you knew his parents weren't there and XX, the coach goes 'what's wrong with $\mathrm{X}$ ' and then they tell them off for not having said. But the player is thinking 'my contract's coming up in a few weeks' and so players try to stretch it another month.” (P4, F3, Late).

\section{Sport-family role conflict}

Six higher order sub-themes reflected components of the overall sport-family role conflict that emerged in all focus groups due to the demands of academy commitments impacting on normal family routines and lifestyle. Few, if any, parents resented the demanding travel routines and the resultant work sacrifices that also impacted financially on the family. However, the challenging nature of these logistical and time issues were clear across each focus group:

Getting the lad here is stressful to me, you know - Monday, Tuesday, Thursday and then the game on Saturday and if you've got work commitments as well. That's the biggest stress - getting here as I have to drive 60 miles each way (P5, F2, Late)

Another parent relayed the same sentiments when disclosing that their travel routine utilized only public transport:

I've been doing it for 3 years - getting the train from $\mathrm{X}$ to here and a taxi from the station to here and back again. Catching the train at $8.20 \mathrm{pm}$ on a Tuesday and Thursday night and we're not getting home till 11.30pm. And then he’s up at 7.30am next day for school (P2, F2, Later).

It was evident that having a son or several sons in an academy was a financial strain for nearly all parents. This was particularly true for those parents who had farther distances to 
1 travel, due to ensuing petrol costs, and those who worked at weekends resulting in loss of

2 earnings. One single mother stated, "It is a big stress for me - my other kids go without so my

3 son goes here"(P7, F2, Early). However, a number of parents agreed that "If they weren't

4 doing football it would be doing something else you'd be funding "(P5, F1, Early) suggesting

5 that participation in football did not transcend normal or expected family financial demands. Whilst some parents developed relationships with other football parents, many parents discussed how their personal and social lives had become one dimensional and non-existent due to their commitment to football. One early specializing parent stated: It's the lack of time at home and splitting the family, and lack of family time due to being here the whole weekend so you can’t have a day out with the family or see

To which another early stage parent, concerned for how future involvement would impact on their lives, added:

"When it gets to U-16 you have to remember some of those lads in those teams are only 14/15 years old; they are training here everyday in the Summer holidays, everyday in the Easter holidays and if you think your life's messed up now, how are you gonna cope with that? (P7, F2, Early).

Finally, parents with other children raised the issue of sibling inequality as a prominent challenge and their resultant experience of guilt associated with perceptions of neglect. Some parents disclosed how they tried to compensate their other children by spending more of their time doing things for them, as one parent reported, "You sometimes try to compensate for that by taking them somewhere else, driving them about where you wouldn’t normally.”(P3, F1, Late). Another parent echoed this sentiment hinting at the problems of resentment felt by siblings: 
It's hard to give the other children the attention when you're away Tuesday, Thursday nights and Saturday mornings. We've got two girls aged 7 and they do feel their noses are being pushed past. Then they play up when you do see them and they wind you up even more, so it's a vicious circle (P8, F2, Early).

\section{School support and education issues}

The final dimension of stressors encompassed specific factors associated with school,

school work, and reconciling the demands of education with the demands of academy

participation. These issues were almost exclusively related to late specializing parents when academy demands were greatest and general educational pressure was heightening with examinations and homework. Early stage parents had not yet reached this transition and indeed many successfully used completion of homework and good schoolwork as basic, contingent criteria for their young son's attendance at the academy (i.e., fail to do your homework $=$ no football).

Two later stage focus groups discussed at length their concerns about their sons physical tiredness from the training and match regime alongside homework and exam pressure. The reality of this regime and how it's effects are manifested at home was articulated by one parent who stated:

He does all his schoolwork on the Wednesday in between the Tuesday and Thursday night sessions. My wife has to wake him up on the Wednesday morning and he comes in at 3.30pm. The next thing happens is I walk in at 4.45pm and I'm waking him up off his bed because he’s just flaked out. (P2, F2, Later).

Parents at this later stage also exchanged their problematic experiences of managing pressure for their son to participate in school sport with sometimes the direct conflict of attendance at the academy. A number of parents referred to the behaviour of certain PE teachers towards their son in these circumstances when they could not attend a school fixture. The following quote serves as a good representation of the issue: 
He (son) plays badminton for the school, does reasonably well at it and he’s told he'll never play for school again... what impression is that making on the kid? And he’s (teacher) saying that my son has got an attitude problem! (P3, F1, Later).

A number of parents also acknowledged concerns over the treatment of their child from an educational perspective because they attended the football academy. The issue not simply being a lack of school support for football, but a fear of unfair academic treatment by teaching staff. Two fathers whose sons had conflicted with a PE teacher over school football attendance were now concerned with how the teacher would treat their sons as an assessor of their examination in sport:

P1: My concern with it now is my son is going to do his GCSE [British examination at 16 years old] in Sport

P4: Snap

P1: Is this teacher gonna hold it against them because a lot of the assessment is done by the teacher watching them play sport?

P4: I said to the teacher 'is this gonna affect him next year? Because I certainly hope it doesn't'. So we have one or two issues with the school, yes.

\section{Discussion}

By using multiple focus groups, the current study engaged the realities facing parents of talented footballers, and delineated between those stressors that were either prolonged across the specializing stage or specific to early and later phases. At a conceptual level, the findings offer further support to the utility of distinguishing between competitive, organizational and developmental-based stressors when supporting parents in their youth sport role (Fletcher et al., 2006; Harwood \& Knight, 2009a,b). In addition, the exchanges between parents often illustrated how their deep desire for success and commitment to their son's football underpinned many of these three dimensions of stressor. Conflict, uncertainty, tension and 'griping' were regular features of the focus group discussions, with academy 
1 practices being fairly central determinants. Competitive stressors emerged through a range of

2 factors associated with matches, some of which appeared to be more pertinent to certain

3 developmental time points. Most notably, a number of early stage parents making the

4 transition to the academy from local youth football appeared to struggle with certain academy

5 expectations and practices. Professional academies tend to adopt strict policies of parental

6 touchline behavior that appropriately forbid coaching and instruction. It is also common

7 developmental practice in the early stages to move players around different positions to aid

8 their understanding of positional demands and to assess the players 'fit' for the future. Whilst

9 a substantial number of parents across the focus groups understood and praised this developmental element of academy policy, including shared game time for all squad players, there were parents at each stage who were clearly and consistently perturbed by certain substitution practices, positional changes, and the reduced focus on winning and intra-squad competition. These parents almost exclusively believed that winning matches and having the best team on the pitch served as the greatest source of confidence for their son and the team. Fear of injury emerged as a stressor across the specializing stage, but was heightened in the later stages due to the increased physical nature of the game, the potential consequences regarding career progression, and the increased tendency for players to mask an injury. Linked to these consequences, their child's level of performance and the anticipation of their son’s negative post-match reactions became more specific stressors discussed within later stage focus groups. This is potentially attributable to the enhanced focus on retaining a place at the academy and the increasing pressure for success and opportunities that are more relevant at 14 and 15 years of age. In summary on these points, whilst the majority of parents viewed their son's participation at the academy as a developmental privilege and applauded mastery-oriented coaching approaches (Smoll \& Cumming, 2006), a number of parents brought an egooriented tension to the focus group, highlighted by a more 'winning is all that matters' 
1 mentality to their son's involvement. The philosophies, behaviors and stressors of these

2 particular parents corresponded with some of the negative parenting practices in tennis

3 identified by Gould et al. (2008).

4

Beyond competitive issues, organizational stressors held a day-to-day prominence in the lives of academy parents. Adapting the organization-based work of Cooper, Dewe, and O’Driscoll (2001), Hanton and Fletcher (2005) forwarded five dimensions of organizational stressor in sport: factors intrinsic to the sport (e.g., finances, time, travel, training, injury); roles in the sport organization (e.g., role ambiguity; expectations; managing role conflicts); sport relationships and interpersonal demands (e.g., with other parents; coaches; teachers/school); organizational structure and climate of the sport (e.g., selection policies; autonomy in decision making; match schedules); and athletic career and performance development issues (e.g., security of position; retention vs release; funding support). Components of these dimensions resonated greatly with parents’ narratives around academy processes, communication, sport-family role conflict and school support. Firstly, even though academies attempt to promote a careful and sensitive developmental approach, they still remain as professional businesses that release young players who fail to attain the appropriate standard. This model of organised youth sport created uncertainty in parents both before and after signing their child for the football academy.

Their son's potential release at the end of a season was a preoccupation for all focus groups. However, this was not aided by parents’ perceptions of the limited information, feedback and communication that they received from their relationship with coaches or the academy overall. In some cases, it appeared that the role that parents wanted to play either did not correspond with or was not information-rich enough in respect to the norms of the academies. Early stage parents recalled concerns about the availability of information and education related to themselves and their sons' involvement in the academy. All focus groups lamented being somewhat excluded from the communication loop, unable to assist in their 
1 son's development, and being treated with a lack of empathy given their personal and social

2 sacrifices.. This particular finding replicates the stressors emergent in specializing stage

3 parents in tennis with respect to lack of feedback from national governing body training

4 camps (Harwood \& Knight, 2009b). Later stage focus groups raised anxieties over the process

5 of release and feared degrees of insensitive conduct on behalf of the academy. Parents cited

6 limited control to help prepare their sons for what might happen yet anticipated the

7 devastating effect that release would have on their child.

It appears likely that the impact of release worsens later in the specializing stage

9 because a child is approaching the investment stage (i.e., a professional academy contract) when his career prospects are dealt a severe blow. Release can therefore be likened to involuntary career termination (Taylor, Ogilvie, \& Lavallee, 2006) and is recognised as a experienced the policy of release as a prolonging stressor due to chronic uncertainty and lack of control. stressors intrinsic to the sport that led to greater sport-family role conflict where the role pressures of being a football parent conflicted with other family activities and responsibilities (Greenhaus \& Beutell, 1985). The lack of attention to other siblings, resultant guilt and compensatory behavior, corresponded directly with the experiences of tennis parents (Harwood \& Knight, 2009a,b; Wolfenden \& Holt, 2005). However, many parents maintained a positive view of their time and financial burden by observing that if they weren't funding football then they'd be funding something else that might 'keep their child off the streets'. Beyond isolated concerns about the consequences of injury, the combination of the physical training regime with school pressures, relationships with the school (including PE teachers) and the management of sport-education conflicts represented prominent developmental issues in the later specializing phase. In concert with the perceptions of 
1 specializing parents of elite tennis juniors (Harwood \& Knight, 2009b), it is at this juncture

2 where demands from academy football, school sport and school work were at their greatest. In

3 two focus groups there were clearly strained relationships between the school, the academy

4 and parents that, as a number of parents voiced, suggested the need for more proactive dialogue between academies and schools in relation to player development and welfare. This included considerations to the training regimen of players during exam periods and the management of player fatigue.

Convergent with findings in youth tennis, whilst football parents talked through many negative and troubling issues, not all of these were accompanied by a sense of strain and an inability to cope (Lazarus, 2006). A limitation of this study is that it did not set out to study sources of strain and coping per se. Whilst the focus group discussions promoted many examples of negative appraisal processes and the disclosure of negative emotions, there was evidence that parents used emotion-focused coping by selectively-attending to the positive aspects of their situation. Namely, that such stressors (e.g., lack of communication and feedback) were acceptable because of the importance they assigned to the opportunity for their son to train at the academy. Whilst it would be remiss of this study not to report the positive tone of many parents about their academy experience, it would be equally negligent to conclude that only a limited room for improvement existed in assisting parents. Various implications can be drawn from this study that are of central importance to practitioners, coaches, and sporting academies when dealing with the parents of talented young players. Firstly, there is a continued premium placed on the early education of parents in relation to the psychological and emotional demands of the specializing stage of youth sport. Such a youth sport education policy would serve to ensure that parents develop the necessary motivation-related knowledge and cognitive-behavioral skills both to manage themselves and to optimally influence the development of their child (Gould et al., 2008). 
1 interactive workshops) where parents gain honest, transparent information on the philosophy

2 and organizational practices of the academy. However, more critically, it may require

3 academies to first reflect on their philosophy of player development and its application. In this

4 study, whilst academies employed certain development-oriented practices, they were also

5 perceived to offer limited 'improvement feedback', grade players weekly (with dubious objectivity), and de-select young players on a yearly basis based on ability. These practices align with a more commodity, performance-based orientation that can represent a professional club’s interest in filtering out weaker players without belief in 'late developers’ or due attention to the emotional impact of release. An academy's reflection of its values and practices in view of potential 'mixed messages' may assist in its explanation to parents about the developmental and non-developmental aspects of its policy.

Subsequently, this points to an agreed understanding of the scope of the parental role and associated expectations within an academy. Communication, monitoring, school-academy relations, and timely feedback pertaining to their child’s progress are particularly sensitive areas for academies to consider alongside greater empathy with the inevitable personal demands facing parents. Attention to such strategies and consistent organizational practices are likely to enhance the perceived value, behavioral roles, and well-being of parents as they progress through this demanding stage of athlete development.

In conclusion, the results of this study underscore the tremendous psychological, emotional, and social investment that characterizes parents of gifted footballers throughout the early to later specializing phase (Côtè, 1999; Wolfenden \& Holt, 2005). The intensive journey of the young academy player is paralleled by a similarly demanding journey for their parents. Only by understanding and appreciating the 'sport parent' might applied researchers and youth sport organizations assist in the process of helping parents to enjoy and optimize their role as a key social agent in their child-athlete's development. 
1 Acknowledgements:

2 This research was supported by the FA as part of it's Psychology for Football research 3 strategy. The authors would like to acknowledge the assistance of Dr. Andy Cale, Head of 4 Player Development and Education.

5 


\section{References}

Baxter-Jones, A.D., \& Maffuli, N. (2003). Parental influence on sport participation in elite young athletes. The Journal of Sports Medicine and Physical Fitness, 43, 250-255.

Bhaskar, R.A. (1975). A realist theory of science. Leeds, UK: Leeds books.

Blumer, H. (1954). What is wrong with social theory? American Sociological Review, 19, 310.

Blumer, H. (1969). Symbolic Interactionism. Englewood Cliffs, NJ: Prentice Hall.

CBS. (2006). Youth game ends up as footbrawl. Retrieved June $21^{\text {st }} 2008$ from http://www.cbsnews.com/stories/2006/09/05/national/main1967336.shtml.

Campbell, D. (1999). Legacies of logical positivism and beyond. In D. Campbell \& M.Jean Russo (Eds.), Social Experimentation (pp 131-144). Thousands Oaks, CA: Sage.

Charmaz, K. (2003). Grounded theory: Objectivist and constructivist methods. In N.K. Denzin \& Y.S. Lincoln (Eds.), Strategies for qualitative inquiry (2 ${ }^{\text {nd }}$ ed., pp. 249-291). Thousand Oaks, CA: Sage.

Cooper, C. L., Dewe, P. J., and O’Driscoll, M. P. (2001). Organizational stress: A review and critique of theory, research, and applications. Thousand Oaks, CA: Sage.

Côtè, J. (1999). The influence of the family in the development of talent in sport. The Sport Psychologist, 13, 395- 417.

Côtè, J., \& Hay, J. (2002). Children’s involvement in sport: A developmental perspective. In J.M. Silva, \& D.E. Stevens (Eds.), Psychological foundations of sport (pp. 484-502). 1 Boston, MA: Allyn and Bacon.

Côtè, J., Salmela, J.H., Baria, A., \& Russell, S. (1993). Organizing and interpreting 3 unstructured qualitative data. The Sport Psychologist, 7, 127-127.

4 Creswell, J.W. (1998). Qualitative inquiry and research design: Choosing among five 5 traditions. Thousand Oaks, CA: Sage. 
1 DeFrancesco, C., \& Johnson, P. (1997). Athlete and parent perception in junior tennis. Journal of Sport Behavior, 20, 29-36.

3 Fish, J., \& Magee, S. (2003). 101 ways to be a terrific sports parent: Making athletics a positive experience for your child. New York: Fireside.

Fletcher, D., Hanton, S. \& Mellalieu, S. D. (2006). An organizational stress review: Conceptual and theoretical issues in competitive sport. In S. Hanton \& S. D. Mellalieu (Eds.), Literature Reviews in Sport Psychology (pp 321-373). Hauppauge, NY: Nova Science.

Fredricks, J.A., \& Eccles, J.S. (2004). Parental influences on youth involvement in sports. In M.R.Weiss (Ed.), Developmental sport and exercise psychology: A lifespan perspective. (pp. 145-164). Morgantown, WV: Fitness Information Technology.

Gould, D., Lauer, L., Rolo, C., Jannes, C., \& Pennisi, N. (2006). Understanding the role parents play in tennis success: a national survey of junior tennis coaches. British Journal of Sports Medicine, 40, 632-636.

Gould, D., Lauer, L., Rolo, C., Jannes, C., \& Pennisi, N. (2008). The role of parents in tennis success: Focus group interviews with junior coaches. The Sport Psychologist. 22, 18-37.

Green, B. C., \& Chalip, L. (1997). Enduring involvement in youth soccer: The socialisation of parent and child. Journal of Leisure Research, 29, 61-77.

Greenhaus, J. H., \& Beutell, N. J. (1985). Sources of conflict between work and family roles. Academy of Management Review, 10, 76-88.

Hanton, S., \& Fletcher, D. (2005). Organizational stress in competitive sport: More than we bargained for? International Journal of Sport Psychology, 36, 273-283.

Harwood, C.G., \& Knight, C.J. (2009a). Understanding parental stress: An investigation of British tennis parents. Journal of Sports Sciences, 27, 339-351.

Harwood, C.G., \& Knight, C.J. (2009b). Stress in youth sport: A developmental examination of tennis parents. Psychology of Sport and Exercise, 10, 447-456. 
1 Hellstedt, J.C. (1990). Early adolescent perceptions of parental pressure in the sport environment. Journal of Sport Behavior, 13, 135-144.

3 Holt, N.L., Tamminen, K.A., Black, D.E., Sehn, Z.L., \& Wall, M.P. (2008). Parental

4 involvement in competitive youth sport settings. Psychology of Sport \& Exercise, 9, 663-

5 685.

6 Hoyle, R. H., \& Leff, S. S. (1997). The role of parental involvement in youth sport participation and performance. Adolescence, 32, 233-243.

Johnson, B. R. (1997). Examining the validity structure of qualitative research. Education, $118,282-292$.

Kirk, D., Carlson, T., O’Connor, A., Burke, P., Davis, K., \& Glover, S. (1997a). The economic impact on families of children's participation in junior sport. Australian Journal of Science and Medicine in Sport, 29, 27-33.

Kirk, D., O’Connor, A., Carlson, T., Burke, P., Davis, K., \& Glover, S. (1997b). Time commitments in junior sport: Social consequences for participants and their families. European Journal of Physical Education, 2, 51-73.

Krueger, R. A., \& Casey, M. A. (2000). Focus groups. A practical guide for applied research (3rd ed.). Thousand Oaks, CA: Sage.

Lazarus, R.S., (2006). Stress and Emotion: A new synthesis. New York: Springer.

Leff, S.S., \& Hoyle, R.H. (1995). Young athlete’s perceptions of parental support and pressure. Journal of Youth and Adolescence, 24, 187-203.

Lichfield, J. (2006, March 10). Obsessive father jailed for tennis player's death. The Independent, p. 22.

Lincoln, Y., \& Guba, E. (1985). Naturalistic inquiry. New York: Sage.

Maykut, P., \& Morehouse, R. (1994). Beginning qualitative research: A philosophic and practical guide. Lewes, UK: Falmer.

Miles, M.B., \& Huberman, A. M. (1994). Qualitative data analysis. London: Sage. 
1 Morgan, D. L. (1997). Focus groups as qualitative research ( $2^{\text {nd }}$ Ed.). London: Sage.Patton, M.Q. (2002). Qualitative research and evaluation methods ( $3^{\text {rd }}$ ed.). Thousand Oaks, CA: Sage.

Ritchie, S.M., \& Rigano, D.L. (2001). Researcher- participant positioning in classroom research. International Journal of Qualitative Studies in Education, 14 , 741- 756.

Sayer, A. (2000). Realism and Social Science. London: Sage.

Shields, D. L., Bredemeier, B. L., LaVoi, N. M., \& Power, C. F. (2005). The behavior of youth, parents, and coaches: The good, the bad, and the ugly. Journal of Research in Character Education, 3, 43-59.

Smoll, F.L., \& Cumming, S.P. (2006). Enhancing coach-parent relationships in youth sports: Increasing harmony and minimizing hassle. In J.M.Williams (Ed.), Applied sport psychology: Personal growth to peak performance (5 ${ }^{\text {th }}$ ed., pp.192-204). New York: McGraw Hill.

Sparkes, A. \& Smith, B., (2009). Judging the quality of qualitative inquiry: Criteriology and relativism in action. Psychology of Sport and Exercise, 10, 491-497.

Taylor, J., Ogilvie, B., \& Lavallee, D. (2006). Career transition among athletes: Is there a life after sport? In J. M. Williams (Ed.) Applied sport psychology: personal growth to peak performance, 595-615. McGraw Hill, New York.

Wolfenden, L.E., \& Holt, N.L. (2005). Talent development in elite junior tennis: Perceptions of players, parents and coaches. Journal of Applied Sport Psychology, 17, 108-126.

Wong, E. (2001). New rules for soccer parents: 1) No yelling, 2) No hitting ref. Retrieved May $27^{\text {th }}, 2008$ from http://query.nytimes.com/gst/fullpage.html?res=9C01E4D61E38F935A35756C0A9679C8 B63\&sec $=$ \&spon= \&pagewanted $=1$.

Woodman, T., \& Hardy, L. (2001). A case study of organizational stress in elite sport. Journal of Applied Sport Psychology, 13, 207-238. 
1 Wuerth, S., Lee, M.J., \& Alfermann, D. (2004). Parental involvement and athletes’ career in

2 youth sport. Psychology of Sport and Exercise, 5, 21-33.

3

4

\section{Figure Caption}

$5 \quad$ Figure 1: Specializing stage parental stressors in youth football 
Figure 1

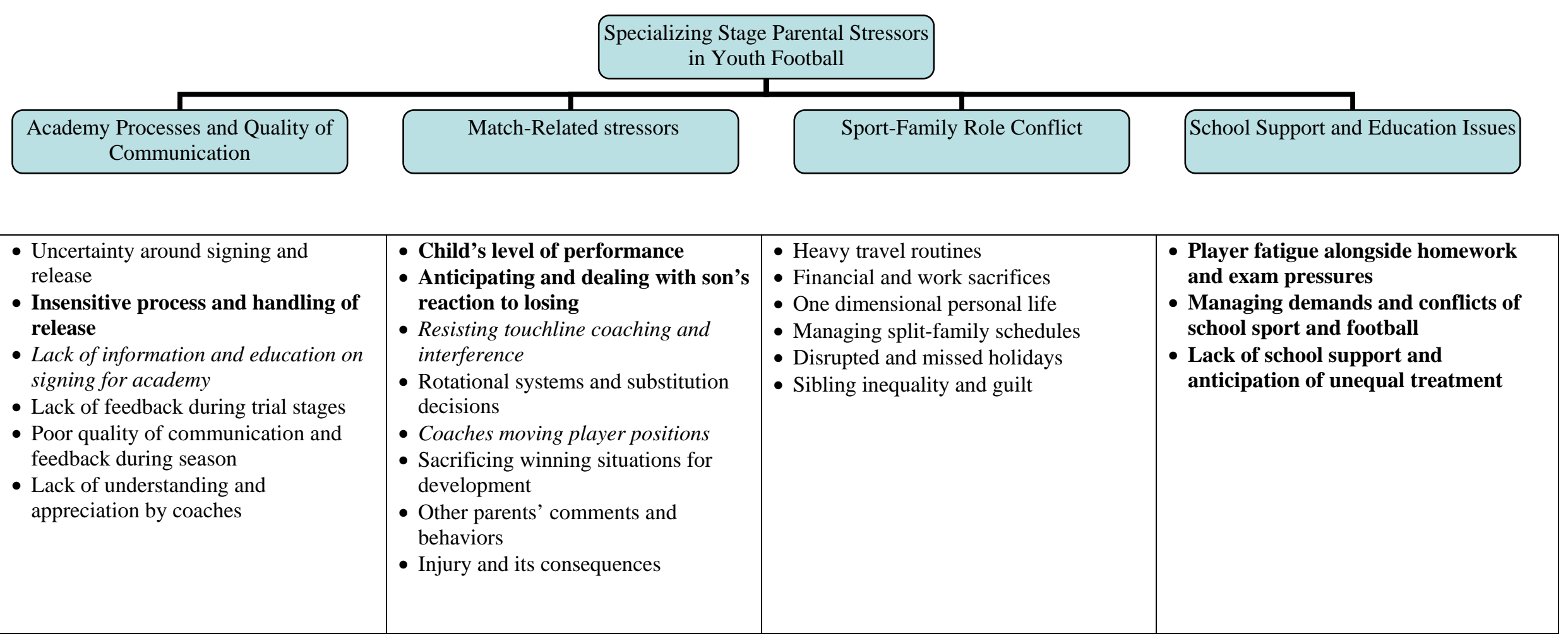

(Note. Normal text indicates themes emerging from both early and late specializing focus groups; text in bold indicates late specializing themes alone; text in italics indicates early specializing themes alone.) 